\title{
14
}

\section{The Role of Coping Skills for Developing Resilience Among Children and Adolescents}

\author{
Tammie Ronen
}

\section{The Effects of Changes, Crises, and Traumas on Children and Adolescents}

Ensuring the wellbeing of children and adolescents comprises a major goal for parents, educators, and mental health professionals. During childhood and adolescence, a wide range of cultural and environmental transformations occur as a result of young people's rapid physiological growth, psychosocial development, and cognitive changes - encompassing increased family responsibilities, rising academic and social demands, separation and individuation from the family unit, and exploration of stressful new experiences with peers and novel adult activities (Steinberg, 2007). Taken together, these developments reinforce the emerging understanding of childhood and adolescence as a critical or sensitive period for the individual's reorganization of regulatory systems, which is fraught with both opportunities and risks (Steinberg, 2013).

The rapid pace of these changes and fluctuations, alongside young people's dependence on adults, renders them vulnerable and sensitive to environmental circumstances that may adversely affect their physical or emotional development (Levendosky, Leahy, Bogat, Davidson, \& von Eye, 2006). This is especially manifested when, in addition to experiencing developmental changes, children and adolescence are exposed to traumatic experiences

T. Ronen $(\varangle)$

Tel-Aviv University, Tel-Aviv, Israel

e-mail: tamie@tauex.tau.ac.il 
within the family (such as neglect, abuse, illness, divorce, death) or to environmental and community stressors and disasters (such as war, terrorist attack, or earthquake). Trauma symptoms have been reported in children as young as one year old (Bogat, DeJonghe, Levendosky, Davidson, \& von Eye, 2006).

Cicchetti $(2006,2013)$ claimed that children's and adolescents' limited life experiences - together with their vulnerability and sensitivity-preclude them from dealing effectively with stress, threats, and crises, which can affect their physical development as well as their personality and emotional development and may predispose them to behavioural, emotional, or cognitive disorders. Other researchers have noted that stressful life events may also impair family relationships, increase behaviour problems, and decrease social competence (Davies, Winter, \& Cicchetti, 2006; Levendosky et al., 2006).

There is no doubt that change, crisis, and trauma render tremendous influence on young people's psychosocial development; however, debates remain about how such experiences impact them. While some traumatic experiences seem to increase the mental health problems of children and adolescents, who demonstrate symptoms ranging from mild distress to severe dysfunction, it appears that other traumatic experiences, paradoxically, seem to affect them positively (Garbarino, 2002).

Two main trends have characterized research studying children's and adolescents' behaviour disorders under adverse conditions. The environmental approach conceptualizes changes and stress as the most important components influencing children's disorders (Levendosky et al., 2006). According to this approach, change (of any kind) acts as a stimulus eliciting stress and anxiety, dependence, and regressive symptoms. It can jeopardize future growth and development, lead to disabling emotional disorders, and leave permanent psychological scars, which are then followed by behavioural and emotional changes and might disrupt the development of basic competencies, threatening the child's ability to process and manage emotions effectively (Martinez-Torteya, Bogat, von Eye $\&$ Levendosky, 2009). The new or exacerbated symptoms might disappear after a short period of time, or they may develop further into post-traumatic stress disorder (PTSD; Garbarino, 2002). For years, research coinciding with the environmental approach has concentrated on the negative consequences of adversity, conceptualized primarily in terms of risks for psychopathology, dysfunction, breakdown, and other adverse impacts on individuals and families (Masten, 2018).

The second group of studies, in line with a resilience approach, has focused on normal development, asserting that children and adolescents generally respond 'normally' even to severe crises. These studies suggest that although 
children may evidence an increase in their frequency of behaviour problems, they often do not develop PTSD after exposure to trauma or stress, and after a time they return to their usual patterns of behaviour, relating to the event as a challenge (Ronen, Rahav, \& Rosenbaum, 2003). Accordingly, while some individuals or families appear to be more vulnerable to adversity, there are others who seem to be better protected or to recover better after exposure to objectively similar traumas or family crises. Sometimes these 'buffering' effects may reflect children's individual functioning at the positive end of a continuum (such as strong levels of emotional regulation or problem-solving) along indices previously shown to exacerbate the risks posed by adversities such as poverty or family violence. In other cases, these young people may have access to 'buffering' environmental influences (like a supportive friend or mentor) that help protect them from the vulnerabilities typically studied in earlier models of stress and coping. According to this approach, resilience is the component that determines the difference between those individuals or families who continue on successfully and those who do not (Angelkovski, 2016).

Positive adjustment in general, and in high-risk samples in particular, demonstrates the influences of personal traits, coping behaviour patterns, and specifically the ability to adapt to change. During recent decades, scholars have shifted their focus from studying trauma and risk to studying personal and environmental strengths and resources in the context of risk or adversity_including capabilities, processes, or outcomes denoted by desirable adaptation (Masten, 2007, 2018). The present chapter upholds the view that stress is a challenge, which requires that children and adolescents be resourceful, cope, and adapt to the changing environment and their changing selves.

\section{Resilience: Definitions and Ecological Levels}

The concept of resilience emerged from the phenomenon of exposure to trauma, crisis, and change that necessitates coping with and living with adversity (Masten, 2007). The construct has several definitions; some highlighted responding to an event (Ungar, 2008) while others defined resilience as a trait characteristic of an individual or family (Luthar, 2006) or even of a community (Pike, Dawley, \& Tomaney, 2010). Others have emphasized resilient processes, outcomes, or patterns (a way of life). Richardson (2002) reviewed three waves in scholars' identification of resilient qualities. The first wave, from the early twentieth century, identified developmental 
assets and protective factors phenomenologically. The second wave, in the mid-twentieth century, described the process of disruption followed by reintegration in order to access resilient qualities. The third wave, exemplifying the postmodern and multidisciplinary view, identified resilience as the force that drives a person to grow through adversity and disruption.

In that vein, this chapter upholds that resilience occurs in the presence of significant adversity or threat. It infers the human capacity for adapting to adversity or overcoming the challenges posed by a threat or pressure while observably maintaining healthy successful functioning or 'bouncing back' after an initial distress response (Masten, 2007, 2018). As part of the tendency to focus on positive virtues and strengths rather than on pathology and risk within the framework of positive psychology, the study of resilience emphasizes its adaptation and coping characteristics. Thus, the goal is not to look at the absence of pathology but rather to pinpoint behavioural and cognitive competencies and the mastery of appropriate developmental tasks that may explain the capacity for resilience (Cornum, Matthews, \& Seligman, 2011; Kim-Cohen, Moffit, Caspi, \& Taylor, 2004; Seligman, 2011). Masten (2018) emphasized the importance of both external adaptation to the environment and an internal sense of wellbeing as part of a comprehensive assessment of resilience. Moreover, resilience is better characterized as a dynamic process, because individuals can be resilient to specific environmental hazards or resilient at one time period but not another (Rutter, 2006). Through growth, children acquire new skills and resources that help them to 'bounce back' and develop an ability to succeed when faced with negative events later in life (Richardson, 2002). Evidently, whether one understands resilience as a developmental outcome, as a set of competencies, or as coping strategies, there is much overlap between these conceptualizations.

Moreover, although the definition of resilience has focused primarily on the individual and his or her outcomes to a traumatic or stressful event, coping also depends to a great extent on the developmental components and social determinants of health surrounding that individual (Luthar, 2006, Luthar, Sawyer, \& Brown, 2006). This is important because resilience is a coping process necessitating the interactions between the child or adolescent and his/her surroundings (Gilligan, 2004). Thus, resilience has been conceptualized as reflecting protective factors at the individual level (e.g., the capacity to navigate health-sustaining resources and seek out opportunities to experience feelings of wellbeing) and also protective conditions in the individual's family, community, and culture that provide these health resources and experiences in culturally meaningful ways (Luthar et al., 2006). Therefore, resilience is influenced by the child's environment, such that the 
interaction between individuals and their social ecologies may determine the degree of positive outcomes experienced. Rutter (2006) emphasized the need for environments such as schools to examine their balance of risk and protective factors in order to build support mechanisms and provide more protective situations.

Furthermore, cultural variation is hypothesized to exert an influence not only on specific children's resilience but also on their local communities' resilience. Pike et al. (2010) asserted that resilience has emerged as a notion seeking to capture the differential and uneven ability of geographical regions to react, respond, and cope with uncertain, volatile, and rapid change. Resilient communities adapt well in the face of adversity, trauma, tragedy, threats, or even significant sources of risk. Pike et al. (2010) emphasized that analysis of regional development and functioning has recently broadened from a mere focus on growth to a wider perspective on regions' relative resilience in responding to the modern world's ever-increasing diverse array of external shocks and transitions, including financial crises, dangerous climate change, terror campaigns, and extreme weather events.

Hence, overall, resilience depends not only on the individual child's or adolescent's developmental pathway and the family and immediate environment, but also on broader community resources. This constellation of characteristics may converge when high-risk, vulnerable children and adolescents grow up happy and successful despite being born and raised under disadvantaged circumstances. In this sense, resilience refers to better-thanexpected developmental outcomes and to the ability for competence under stress (Ungar, 2008).

\section{Basic Components Encompassing Resilience}

As discourse on childhood and adolescence has expanded to focus on health instead of just on illness, Rutter (2006) underscored the need to relate to the correlations between risk and protective factors in explaining the processes underlying resilience. With regard to risk dimensions at the individual level, Seligman (2011) offered the ' 3 Ps' of resilience-three perception distortion tendencies that can hinder recovery from adversity: personalization, pervasiveness, and permanence. Personalization is a cognitive distortion that makes people believe they are to blame for every problem, instead of looking at other, outside factors that may play a part in the adverse situation. People should take responsibility for a failure, but they should not see themselves as a failure. Pervasiveness refers to the distorted belief that an adverse event will 
affect all areas of life instead of just one. People who have this mindset may find it hard to carry on with life because they feel there is no way out of their situation. Permanence is the distorted belief that one's feelings or situation will last forever. This may cause the person to feel overwhelmed. The truth is that time passes by, and life's challenges go with it. Pain and pleasure are temporary. By recognizing these thoughts and beliefs as counterproductive, individuals can better understand their own tendencies to perceive situations, events, and themselves and can learn to foster resilience.

With regard to the vulnerability and protective factors explaining the processes underlying resilience, such dimensions characterize not only the individual child or adolescent but also the factors at play in the young people's social and political context (Luthar, 2006; Luthar et al., 2006), spanning the family and community levels. The fact that some children and adolescents develop and function successfully even under dire circumstances accentuates the need for parents and professionals to become aware of the very different resources that may sustain young people's wellbeing in various families and communities under stress, especially in schools.

Importantly, children and adolescents are capable of learning new skills that can increase their likelihood of adaptation to adversity (Luthar et al., 2006; Shannon, Beauchaine, Brenner, Neuhaus, \& Gatzke-Kopp, 2007). Studies have pinpointed coping resources (Folkman, 2008) and learned resourcefulness (Rosenbaum, 1990, 2000) as crucial variables affecting the human response to stress. Among such skills, Ungar (2008) mentioned the importance of a sense of belonging, personal meaning, the experience of self-efficacy, life skills, vocational competencies, and the expression of one's cultural and ethnic identification as aspects of healthy functioning associated with resilience (Ungar, Ghazinour, \& Richter 2013).

The next sections of this chapter discuss some resilience-related skills mentioned in the literature. These include individual components such as self-control skills, self-efficacy, subjective wellbeing in general, and positive affect in particular, as well as familial and environmental components such as social support and interpersonal relationships.

\section{The Role of the Individual in Developing Resilience}

Self-control skills. Research has shown that self-control is of great importance to human psychological health and involves a crucial personal component for coping with stressful events—therefore a major element for 
becoming resilient (Ronen \& Rosenbaum, 2010). The human desire to control is powerful, and the feeling of control is rewarding, while the loss of control is the main reason for the development of a large range of disorders. Hence, it is important to help children and adolescents feel that they can control situations (Gilbert, 2005).

Self-control may therefore be viewed as a coping mechanism, as skills and strategies, or as a protective factor in coping with life's demands. Selfcontrol comprises a goal-directed learned repertoire of behaviours that help people overcome stressful situations, pain, and disturbing emotions and be more resilient (Rosenbaum, 1990, 2000). This repertoire of self-control skills enables people to act upon their aims, overcome difficulties, delay gratification, and cope with distress. Thus, it targets both internal as well as external disturbing situations. Self-control necessitates that people assess disruptions in their habitual way of thinking, believe that their actions can improve their coping, and expect themselves to be capable of creating the desired change.

A considerable body of research has previously shown that children and adolescents who were high in self-control behaviours-such as postponing gratification, planning the future, and using cognitions to guide actions - were less likely to behave aggressively (Blair, Denham, Kochanoff, \& Whipple, 2004; Gyurak \& Ayduk, 2008). Self-control skills are positively related to students' academic competence and performance, independent of general intelligence, cognitive ability, and prior achievements (Liew, Chen, \& Hughes, 2010; Valiente, Swanson, Lemery-Chalfant, \& Berger, 2014).

Self-control skills increase coping both via a direct main effect and an indirect buffer effect. Directly, self-control increases one's sense of value, selfefficacy, or self-evaluation while feeling support from others. The buffer effect refers to the decreased negative impact experienced as an outcome of stress and becoming more resilient (Ronen \& Rosenbaum, 2010). Self-control can also have an effect on one's subjective wellbeing by mediating the connection between stress and subjective wellbeing, thereby influencing a person's primary or secondary appraisal of the distressing situation. Conceiving support as more available leads to better feelings about one's ability to cope, to evaluate and resolve problems, and to decrease the potential threat (Orkibi \& Ronen, 2015, 2017).

Studies of Israeli adolescents have found significant links between high self-control skills and fewer negative emotions, as well as higher self-efficacy beliefs, positive emotions, and a higher positivity ratio and ability to be resilient while facing stress. For example, among children and adolescents, during the first and the second Gulf Wars in Israel, higher levels of self-control skills were connected to lower levels of fear and to fewer symptoms (Ronen 
et al., 2003; Ronen \& Seeman, 2007). The existence of self-control skills was also found to enable the development of fewer symptoms while facing parents' divorce or sickness (Hamama \& Ronen-Shenhav, 2012; Ronen, Hamama, Rosenbaum, \& Mishely-Yarlp, 2014).

Traditionally, self-control skills have been associated with reductions in maladaptive outcomes such as aggressive behaviour. Students with higher self-control skills reported a less hostile attribution bias (i.e., interpreting others' intentions or behaviours as hostile and threatening) and less physically aggressive behaviour (Agbaria, Hamama, Orkibi, Gabriel-Fried, \& Ronen, 2016). Further, self-control skills have been associated with increases in adaptive outcomes such as interpersonal and prosocial outcomes. Studies have demonstrated that when students showed high self-control skills, they reported higher perceived social support than their peers with low self-control skills (Orkibi \& Ronen, 2015; Ronen, Abuelaish, Rosenbaum, Agbaria, \& Hamama, 2013) as well as a higher rate of positive emotions and the subjective cognitive appraisal of being happy (Gilbert, 2005; Ronen et al., 2014). Some researchers view self-control as resulting from positive emotions because the latter create a good foundation for applying skills to achieve goals (Baumeister \& Sparks, 2008; Baumeister, Vohs, DeWall, \& Zhang, 2007; Tice, Baumeister, Shmueli, \& Muraven, 2007). Considering that self-control skills have been highlighted as a crucial component in coping with crisis and in maintaining high levels of subjective wellbeing, it may be assumed that children and adolescents who possess a higher level of self-control skills will achieve higher levels of subjective wellbeing and develop better resilience.

Self-efficacy. Whereas self-control relates to behaviour, self-efficacy relates to beliefs about oneself. Self-efficacy comprises beliefs in one's capabilities to organize and execute the courses of action required to achieve one's goals (Bandura, 1997). Efficacy beliefs influence thought patterns, which can then enhance or undermine performance (Bandura, 1997). Such beliefs shape the plans and behaviours that people choose to pursue, how much effort they put forth in given endeavours, how long they will persevere in the face of obstacles and failures, their resilience to adversity, and whether their thought patterns are self-hindering or self-aiding. Thus, perceived self-efficacy may constitute a primary mediation agent in behavioural change.

Stronger perceived self-efficacy leads people to set higher personal goals and to commit themselves more firmly (Bandura, 1997). Inasmuch as challenging goals raise the level of motivation and performance attainments, the capacity to influence one's own process of change actually comprises a component of control (Bandura, Caprara, Barbaranelli, \& Pastorelli, 2001). Thus, once a person possesses the necessary self-control skills, it is crucial for the 
person to believe that $s /$ he possesses those skills and that $s /$ he is capable of executing the actions needed to achieve the desired change.

By predicting outcomes, people foster adaptive preparedness and exercise control that helps bring significance to their lives (Bandura et al., 2001). The way people think or believe in their own ability constitutes a most important feature in the process of change and may best be predicted by the combined influence of efficacy beliefs and the types of performance outcomes expected within given social systems (Bandura, 1997). The outcomes people anticipate depend largely on their judgement as to how well they will be able to perform and the anticipated consequences (Bandura, 1997). For example, Ronen, Hamama, and Rosenbaum (2013) found that children who wet the bed at night were able to overcome their bedwetting when they actively participated in predicting the process of change, such as their pace of decreasing weekly bedwetting frequency. Thus, predicting outcomes can become an important component involving children's beliefs and the change process itself (Masten, 2007).

Self-efficacy has also been found to correlate with wellbeing. For instance, studies of Israeli adolescents revealed significant links between stronger selfefficacy beliefs and a higher positivity ratio - the positive ratio between positive emotions to negative emotions - which is an indication of a high level of wellbeing (Orkibi \& Ronen, 2015; Ronen \& Seeman, 2007). Self-efficacy was also shown to be important for improving family life and happiness (Waters, 2011, 2015). Caprara, Steca, Gerbino, Paciello, and Vecchio (2006) reported that self-efficacy was a significant determinant of happiness.

Becoming active in change processes, believing in one's ability to influence change, and predicting one's own outcomes are all acquired skills (Rosenbaum, 1990, 2000). These crucial components in the process of change are skills needing to be taught and practiced with clients (Masten, 2007; Ronen \& Rosenbaum, 2010). Considering that self-efficacy beliefs have been pinpointed as a crucial component in overcoming difficulties and stress as well as in becoming happier and increasing wellbeing, it may be assumed that children and adolescents who possess a higher level of self-efficacy are more likely to develop better resilience.

Positive affect. Researchers have claimed that happiness is a protective or coping mechanism to help children and adolescents become resilient. Studies have presented good outcomes for happy people, who appear to be less aggressive and less anxious, to have better interpersonal relationships, and to be more inclined to be kind and charitable (Keyes, 2006, 2013; Lyubomirsky, King, \& Diener, 2005). 
Within the framework of positive psychology, happiness has been studied as a positive personal resource, as a major life goal, and as a factor important for the optimal flourishing and functioning of people, groups, and institutions (Carr, 2004; Frederickson, 2009; Gable \& Haidt, 2005). Keyes (2006, 2013) suggested that happiness incorporates two abilities: achieving subjective wellbeing by expressing positive emotion, and achieving positive functioning towards oneself and one's environment. Research showed that in order to become happier, people need to gain a sense of mastery, connectedness, and self-acceptance (Keyes, \& Simos, 2012). Being happy does not mean that people do not experience stress, crises, or problems; rather, happiness encompasses a 'secret weapon' in trying to cope with such distress. For example, 'happy' people may understand that although distress exists, happy moments will return and one can work towards achieving more happiness (Diener, 2019; Keyes, 2006; Lyubomirsky et al., 2005; Ryff, 2014).

Many concepts relate to happiness: subjective wellbeing, satisfaction with life, flourishing, thriving, and more. The present chapter focuses on positive affect as an easier concept to explain, assess, and teach children and adolescents to be aware of and use.

Emotions have long been recognized as a major cause of human behaviour. Positive emotions increase positive human behaviour (Fredrickson, 2009). Positive emotions like enthusiasm, pride, and determination operate as independent bipolar constructs from negative emotions (e.g., fear, frustration, guilt), so that the existence of one does not necessarily point to a lack of the other (Bradburn, 1991; Watson, Clark, \& Tellegen, 1988). Research has shown that the psychological impacts of unpleasant phenomena outweigh those of pleasant phenomena (Baumeister \& Sparks, 2008) and that the impact of good events dissolves more rapidly than the impact of bad events, whereas a single bad event has greater impact than a comparable good event (Baumeister et al., 2007). Thus, it takes a larger quantity of positive emotional experiences to counteract the impact of adverse ones.

Positive affect and negative affect are often studied as part of a positive-negative rating scale (Watson et al., 1988). Positive emotions broaden momentary thought-action repertoires, resulting in a higher likelihood of pursuing a wider range of thoughts and actions, because one can see more possibilities (Fredrickson, 2009). While positive affect correlates with satisfaction from life as well as with high levels of self-confidence and a richer social life (Bood, Archer, \& Norlander, 2004), negative affect correlates with reports of stress symptoms (Bood et al., 2004; Seligman, Steen, Park, \& Peterson, 2005). Negative affect narrows momentary thought-action repertoires and 
causes humans to see fewer opportunities (Fredrickson, 2009; Magyar-Moe, 2009).

The experience of positive emotions is associated with better functioning and, in the long run, correlates with enhanced physical, intellectual, and social resources (Johnson, Waugh, \& Fredrickson, 2010). It is therefore a crucial component for achieving resilience.

In several studies, we demonstrated the importance of positive affect for children's and adolescents' coping. Coping is regarded as an internal mechanism within the individual, which comprises a main way to manage diverse situations in life and to master environmental and internal conflicts, and thus to develop resilience (Folkman, 2008). Adolescents were shown to cope better with fear of wars and missile attacks when they maintained positive affect (Ronen \& Seeman, 2007). Among Arab adolescents, lower rates of symptoms and of aggression emerged when they could express higher levels of positive affect (Ronen, Abuelaish et al., 2013), and when Israeli students expressed positive affect, they flourished, even while under exposure to risk (Orkibi \& Ronen, 2015).

Thus, teaching children and adolescents to express positive affect, to overcome negative affect, and to look for activities and situations that increase their happiness may be major tools for helping them become more resilient, cope with difficulties, and be able to flourish.

\section{The Role of the Family and Peers in Developing Resilience}

The previous section presented self-control skills, self-efficacy, and positive affect as individual coping mechanisms for helping children and adolescents achieve resilience. However, children do not grow up alone; their family and society hold main roles in helping them develop those resilience skills. As Gilligan (2004) stated, while resilience may previously have been seen as residing in the person as a fixed trait, it is now more usefully considered as a variable quality that derives from a process of repeated interactions between a person and favourable features of the surrounding context in that person's life. The degree of resilience displayed by a person in a certain context may therefore be said to be related to the extent to which that context has elements that nurture this resilience. It is therefore important to ask: How can families and communities increase resilience among children and adolescents? How can we train them to do so? 
The desire to belong and to form attachments with family and friends is considered a fundamental human need. Multiple positive health and adjustment effects have been associated with a sense of belonging and with interpersonal attachments. It is also through supportive relationships that selfesteem and self-efficacy are promoted. Having social competence and having positive connections with peers, family, and prosocial adults are significantly related to children's ability to adapt to life stressors (Masten, 2007).

Family-level protective factors include resources and supportive relationships, such as family coherence, stable caregiving, and parental relationships. Children whose mothers are available and supportive developed selfregulation, self-efficacy, and self-esteem abilities. (Grolnick \& Ryan, 1989). Strength-based parenting, parental warmth, support, positive expectations, and low derogation predict children's behavioural and emotional adaptation under a wide variety of adverse circumstances (Kim-Cohen et al., 2004). Parents who are aware of and use their children's strengths enable them to enhance their self-efficacy beliefs, thus resulting in higher levels of wellbeing (Waters, 2011, 2015). Effective parenting is associated with decreased externalizing behaviours and increased positive adaptation (Levendosky et al., 2006).

For children, the development of friendships and the ability to get along with peers individually and in groups is paramount. Friendships provide support systems that can foster emotional, social, and educational adjustment. Positive peer relationships have been shown to protect children during times of family crisis. Being part of at least one best friendship may also improve children's adjustment. As children enter adolescence, these friendships may carry even more weight, as teens shift from being dependent on their immediate environment (the parents) to relating more to their peers. Society plays major roles in affecting adolescents' self-identity, self-image, and self-evaluation (Steinberg, 2007).

Social support encompasses personal, social, and familial relationships (Sarason \& Sarason, 1990). In the course of adolescence, relations with peers become a more central source of social support, and perceived support from parents either remains constant or decreases. Research has identified four kinds of social support: informative, instrumental, emotional, and companionship (House, 1981). The need for relatedness (the emotional and companionship aspects of support) refers to the need to feel significant, connected to, and cared for by important others rather than isolated or disconnected from others (Milyavskaya \& Koestner, 2011). During recent decades, social support has been identified as one of the most crucial factors 
helping human beings cope, overcome difficulties, and enable a healthy lifestyle (Keyes, 2006, 2013; Keyes \& Semoes, Simoes 2012).

In all our studies, we have found that children and adolescents presented higher levels of wellbeing and a greater ability to flourish-even when exposed to terror, war, and aggression-when they had either family support or peer support (Orkibi \& Ronen, 2015; Ronen et al., 2014). We can therefore conclude that children and adolescents can be resilient once they acquire the basic needed skills and live in a protective supportive environment of family and peers. Parents and communities can help enable children and adolescents to become resilient, which is important because professionals, on the one hand, can train children to enhance their social skills for obtaining support from others and, on the other hand, can train parents and families to increase children's strengths, focus on those strengths, and help them express positive affect on the path towards greater resilience.

\section{The Role of Schools in Developing Resilience}

A major focus of research into resilience has investigated close figures in the child's and adolescent's extrafamilial environment as influencing young people's coping ability. Beyond examining individual developmental pathways of vulnerable children and youth and their family resources as discussed previously, these studies have explored the health-enhancing capacities of the community and, especially, of the school system. Thus, protective factors at the community level may include peer relationships, non-family-member relationships, non-family-member social support, and religion, among others (Keyes, 2006; Gavriel-Fried \& Ronen, 2016; Orkibi, Hamama, GabrielFried, \& Ronen, 2018).

There is broad agreement among educators, policymakers, and the public that schools are the child's main life setting and has an important role to play in raising healthy children, by not only fostering their cognitive development but also their social and emotional development (Durlak, Weissberg, Dymnicki, Taylor, \& Schellinger, 2011; Wehmeyer \& Shogren, 2017). Considering the amount of time the average child spends at school during their lifetime, the influence of schools should never be underestimated (e.g., Howard \& Walton, 2015). Schools provide environments for children with opportunities for positive peer interactions, significant relationships with adults other than their parents/caregivers, and promotion of social and emotional learning (Graham, Phelps, Maddisson, \& Fitzgerald, 2011; Howard \& Walton, 2015). Many schools have well-developed programs 
aimed at building resilience that are implemented across the board by teachers (Nolan, Taket, \& Stagnitti, 2014). Educators can choose to enhance, or add to, these programs for the benefit of their students, employing various explicit or implicit strategies in doing so.

Students' self-control skills are linked directly to their resiliency and wellbeing at school and may also be mediated through students' perceived satisfaction of their basic psychological needs; hence, attaining basic needs at school is a key feature determining wellbeing (Ryan \& Deci, 2000). Ryan and Deci (2000) posited that the satisfaction of students' basic needs for autonomy, relatedness, and competence is crucial for students' motivation, optimal development, effective functioning, and good health (Milyavskaya \& Koestner, 2011). At school, subjective wellbeing consists of school satisfaction and the experience of more frequent positive emotions than negative emotions in school, as well as feeling confident, protected, a sense of trust, and autonomy-which enables students' development of self-determination (Wehmeyer \& Shogren, 2017).

In the United States, students who were higher on school satisfaction also scored significantly higher on measures of general life satisfaction, hope, and internal locus of control. Good teacher-student relationships and perceived peer social support are the basic components needed to achieve resiliency and wellbeing (Jiang, Huebner, \& Siddall, 2013) as well as better in-school behaviour (Suldo, Bateman, \& Gelley, 2014). School satisfaction was positively linked with positive emotions in school and negatively linked with negative emotions in school (e.g., Long, Huebner, Wedell, \& Hills, 2012). Perceived goal mastery and teacher and peer support were significantly linked to school engagement and hope, whereas perceived autonomy was also linked to academic achievement in middle and high school students in the United States (Van Ryzin, 2011). In an extensive line of studies with Chinese adolescent students, wellbeing in school was generally significantly linked to perceived social support, scholastic competence, and social acceptance, and predicted students' sense of school belonging and students' wellbeing in school (Liu, Tian, Huebner, Zheng, \& Li, 2015; Tian, Chen, \& Huebner, 2014).

The field of positive psychology strives to understand the strengths within individuals, families, and even communities, and what they need to flourish. It is therefore natural to place emphasis on positive education to develop the art of 'bouncing back' - the ability to spring back from negative events to live a high-quality life (Angelkovski, 2016). An important purpose of educational institutions is to equip students with the essential life skills required to become competent members of society after they complete their school years 
(White \& Waters 2015). One of those vital capabilities is developing the capacity to be resilient. From an education perspective, children and adolescence should understand that things do not always go according to plan, and that remaining positive in these instances can help to ensure the best possible outcome (Angelkovski, 2016). In line with this view, we reasoned that because self-control skills are goal-directed skills that help people regulate their emotions, they will lead to greater self-determination in terms of helping students experience a greater sense of autonomy, volition, and selfendorsement of their behaviour in school as well as a sense of relatedness, belonging, and genuine connection with teachers and peers, and a sense of competence by enabling them to effectively interact with their school environment and maximize opportunities to express or develop their capabilities and strengths (Orkibi \& Ronen, 2017).

\section{Resilience-Promoting Projects}

Many projects have developed over the last decade to impart resilience skills to children and adolescents. Their shared components entail interactive identification of protective factors, free play, behavioural methods, rehearsal, training in relaxation and self-control techniques, practice in generalizing the acquired skills, active parent involvement, and harnessing of teachers' strengths (Alvord \& Grados, 2005; Lavy, 2019).

In three large-scale national projects adopted by the Israeli government, our research and intervention team has targeted children and adolescents to impart self-control skills for decreasing behavioural disorders, increasing positive affect, and enhancing resilience. Each of the three projects started as a university-based controlled trial, implemented by university students to children and adolescents. As research outcomes supported these interventions' efficacy, we started training teachers and educators in the field to apply these resilience-promoting projects as part of their regular school curricula while initially receiving supervision from us. Today, schools all over Israel now apply these projects independently.

The first project, initially called Be Strong (Ronen, 1994), offered children and adolescents a weekly course (adapted to age level) that focused on 'how to become strong'. Participants first learned about strong people in the history of the world and in their country. They identified the characteristics and strengths that helped these people. Second, participants learned about human beings in general, while focusing on the links between thoughts, emotions, and behaviours in order to understand how people process experiences and 
function. In the third phase, participants observed and charted their own behaviours, trying to understand antecedents of those behaviours, the way they process information, and the links between their behaviours and their environment's responses. They learned self-control skills and practiced them both at school and after school. In the last phase, each participant was asked to set a goal for change and to implement it using the material they had learned. The course was taught using the scientific method, where participants had to raise hypotheses about their own behaviours and find ways to observe and try to support those hypotheses.

Evaluation of the initial university-based program demonstrated that participating children and adolescents were able to change their behaviour, apply self-control skills, reduce behaviour problems such as disobedience or aggression, and improve prosocial goals such as increasing their social skills or number of friends. Higher self-control skills were found among those who participated in the program in comparison to classmates who were on the waiting list to begin the program.

This program was also adapted to small groups of high-risk aggressive young people, who studied their own aggressive patterns and thus learned to change their hostile thoughts and negative affect and to express more positive affect. This program targeting at-risk youth, called Empowering Children and Adolescents, is applied nationwide by the Israeli Ministry of Education. A controlled study assessing participating children/adolescents and their parents and teachers demonstrated substantial increases in self-control skills, prosocial behaviour, and school achievements alongside decreases in aggressive behaviour, showing significantly better outcomes compared to waitlisted students (Ronen \& Rosenbaum, 2010).

Next, we were interested in learning if effective intervention requires explicit verbal training or if children and adolescents could boost their selfcontrol skills and resilience by engaging consistently in structured activities that they enjoy, such as sports or music. In our Through Sports intervention, students who were assessed by their teachers as aggressive were offered the opportunity to join an extracurricular afterschool program involving six hours of sports each week, which integrated challenging and competitive athletic activities. The physical education teachers or coaches oversaw the program, and our only request was for them to give students feedback on their participation and to help students set goals each time for the next sports practice. Our controlled study of the program's effectiveness demonstrated two different paths for reducing aggression among the student participants: One way was to reduce hostile thoughts and angry feelings, and the other way was to promote positive thinking and positive affect. Compared to peers who 
did not participate in the sports program, participants revealed significantly higher levels of self-control skills, positive affect, and happiness (Shachar, Ronen-Rosenbaum, Rosenbaum, Orkibi, \& Hamama, 2016).

In another extracurricular program, Sulamot: Music for Social Change, we targeted the same goals via music. Together with the Israeli Philharmonic, we established children's orchestras in boarding schools and institutions for children at risk, teaching all students to play an instrument and participate in the school's orchestra. Empirical studies showed that even those children who were hyperactive, who were diagnosed with attention deficit disorders, who had been sexually or physically abused, or who had not successfully learned to read and write were able to learn musical notation, instrument playing, and skills of coordinating with peers in the orchestra. These studies (master's theses and doctoral dissertations available only in Hebrew) demonstrated that playing music regularly in such high-status orchestras enabled children to reduce aggression, increase self-control and happiness, and become similar to children who were not assessed as high-risk.

\section{Conclusion}

The concept of resilience has been proposed as an answer to help young children and adolescents cope with exposure to change, crisis, and traumawhether in low-risk or high-risk populations. Over recent years, it has become apparent that every human being faces difficulties in life, even young people in childhood and adolescence, and that trauma is not a direct outcome of an event but rather the way one deals with it. It is therefore necessary for all those involved in caring for, raising, and teaching young persons to work towards resilience as a developmental resource or set of natural coping skills for each individual child, in order to increase wellbeing and happiness and to better cope with the challenges, fluctuations, and adversities encountered in life.

Thus, the facilitation of children's and adolescents' resilience must be a shared undertaking by parents, extended family, schools, and the community-to impart them with those skills and to set up optimally protective environmental conditions. In addition to nurturing children and ensuring that their basic needs are met for food, sleep, and warmth, the adults in their lives should foster trust, confidence, the ability for healthy relationships, joyful and satisfying experiences, and self-acceptance. Children and adolescents who attain these crucial skills will be more resilient to deal with whatever they encounter in their lives. 
Taking this approach one step further by describing resilience as a quality of the broader societal environment as much as of the individual and his/her closer circles, policymakers may do well to pay 'careful attention... to the structural deficiencies in our society and to the social policies that families need in order to become stronger, more competent, and better functioning in adverse situations' (Seccombe, 2002, p. 385). This view of resilience that integrates multilevel factors related to individual dispositions, family resources, community opportunities, and social policy offers hope for improving resilience in significant ways, thereby 'changing the odds', especially for at-risk children, rather than expecting individual-level change alone to 'beat the odds' (p. 385).

\section{References}

Agbaria, Q., Hamama, L., Orkibi, H., Gabriel-Fried, B., \& Ronen, T. (2016). Multiple mediators for peer-directed aggression and happiness in Arab adolescents exposed to parent-child aggression. Child Indicators Research, 9(3), 785803. https://doi.org/10.1007/s12187-015-9346-y.

Alvord, M. K., \& Grados, J. J. (2005). Enhancing resilience in children: A proactive approach. Professional Psychology: Research and Practice, 36 (3), 238-245. https:// doi.org/10.1037/0735-7028.36.3.238.

Angelkovski, R. (2016). Education matters. Journal of Student Engagement, 6(1), 39-45.

Bandura, A. (1997). Self-efficacy: The exercise of control. New York: Freeman.

Bandura, A., Caprara, G. V., Barbaranelli, C., \& Pastorelli, C. (2001). Sociocognitive self-regulatory mechanisms governing transgressive behavior. Journal of Personality and Social Behavior, 80, 125-135.

Baumeister, R. F., \& Sparks, E. A. (2008). If bad is stronger than good, why focus on human strength? In S. J. Lopez (Ed.), Positive psychology: Exploring the best in people (Vol. 1, pp. 54-79). Westport, CT: Praeger.

Baumeister, R. F., Vohs, K. D., DeWall, N. C., \& Zhang, L. (2007). How emotion shapes behavior: Feedback, anticipation, and reflection, rather than direct causation. Personality and Social Psychology Review, 11, 167-203. https://10.1177/1088868307301033.

Blair, K. E., Denham, S. A., Kochanoff, A., \& Whipple, B. (2004). Playing it cool: Temperament, emotion regulation, and social behavior in preschoolers. Journal of School Psychology, 42, 419-443.

Bogat, G. A., DeJonghe, E. S., Levendosky, A. A., Davidson, W. S., \& von Eye, A. (2006). Trauma symptoms among infants who witness domestic violence toward their mothers. Child Abuse \& Neglect: the International Journal, 30, 109-125. https://doi.org/10.1002/j.1556-6676.1996.tb01881.x. 
Bood, S. A., Archer, T., \& Norlander, T. (2004). Affective personality in relation to general personality, self-reported stress, coping, and optimism. Individual Differences Research, 2, 26-37.

Bradburn, I. S. (1991). After the earth shook: Children's symptoms 6-8 months after a disaster. Advance of Behavior Therapy, 13, 173-179.

Caprara, G. V., Steca, P., Gerbino, M., Paciello, M., \& Vecchio, G. M. (2006). Looking for adolescents' well-being: Self-efficacy beliefs as determinants of positive thinking and happiness. Epidemiology and Psychiatric Sciences, 15(1), $30-43$.

Carr, A. (2004). Positive psychology: The science of happiness and human strength. New York: Hove and Brunner-Routledge.

Cicchetti, D. (2006). Development and psychopathology. In D. Cicchetti, \& D. Cohen (Eds.), Developmental psychopathology: Vol. 1. Theory and method (2nd ed., pp. 1-23). Hoboken, NJ: Wiley. https://doi.org/10.1002/9780470939383.ch1.

Cicchetti, D. (2013). Annual research review: Resilient functioning in maltreated children: Past, present, and future perspectives. Journal of Child Psychology and Psychiatry, 54, 402-422. https://doi.org/10.1111/j.1469-7610.2012.02608.x.

Cornum, R., Matthews, M. D., \& Seligman, M. E. P. (2011). Comprehensive soldier fitness: Building resilience in a challenging institutional context. American Psychologist, 66 (1), 4-9. https://doi.org/10.1037/a0021420.

Davies, P. T., Winter, M. A., \& Cicchetti, D. (2006). The implications of emotional security theory for understanding and treating childhood psychopathology. Development and Psychopathology, 18, 707-735.

Diener, E. (2019). The science of well being. Journal of Innovation and Entrepreneurship, 37, 1-10.

Durlak, J. A., Weissberg, R. P., Dymnicki, A. B., Taylor, R. D., \& Schellinger, K. B. (2011). The impact of enhancing students' social and emotional learning: A meta-analysis of school-based universal interventions. Child Development, 82(1), 405-432.

Folkman, S. (2008). The case for positive emotions in the stress process. Anxiety Stress and Coping, 21, 3-14.

Fredrickson, B. L. (2009). Positivity. New York: Crown.

Gable, S. L., \& Haidt, J. (2005). What (and why) is positive psychology? Review of General Psychology, 9, 103-110.

Garbarino, J. (2002). Forward: Pathways from childhood trauma to adolescent violence and delinquency. Journal of Aggression, Maltreatment, and Trauma, 6(1), xxv-xxxi.

Gavriel-Fried, B., \& Ronen, T. (2016). Positive emotions as a moderator of the associations between self-control and social support among adolescents with risk behaviors. International Journal of Mental Health in Addiction, 14, 121-134. https://doi.org/10.1007/s11469-015-9580-z.

Gilbert, D. (2005). Stumbling happiness. New York: Vintage.

Gilligan, R. (2004). Promoting resilience in child and family social works: Issues for social work practice, education and policy. Social Work Education, 23(1), 93-104. 
Graham, A., Phelps, R., Maddisson, C., \& Fitzgerald, R. (2011). Supporting children's mental health in schools: Teacher views. Teachers and Teaching: Theory and Practice, 17(4), 479-496.

Grolnick, W. S., \& Ryan, R. R. (1989). Parents styles associated with children's selfregulation and competence in school. Journal of Educational Psychology, 81(2), $143-154$.

Gyurak, A., \& Ayduk, Ö. (2008). Resting respiratory sinus arrhythmia buffers against rejection sensitivity via emotion control. Emotion, 8, 458-467.

Hamama, L., \& Ronen-Shenhav, A. (2012). Self-control, social support, and aggression among adolescents in divorced and two-parent families. Children and Youth Services Review, 34, 1042-1049. https://doi.org/10.1016/j.childyouth. 2012.02.009.

House, J. S. (1981). Work, stress and social support. Reading, MA: Addison Wesley.

Howard, S., \& Walton, R. (2015). Educational psychology: Foundations of learning and development. Macksville, NSW, Australia: David Barlow.

Jiang, X., Huebner, E. S., \& Siddall, J. (2013). A short-term longitudinal study of differential sources of school-related social support and adolescents' school satisfaction. Social Indicators Research, 114, 1073-1086. https://doi.org/10.1007/ s11205-012-0190x.

Johnson, K. J., Waugh, C. E., \& Fredrickson, B. L. (2010). Smile to see the forest: Facially expressed positive emotions broaden cognition. Cognition and Emotion, 24(2), 299-321. https://doi.org/10.1080/02699930903384667.

Keyes, C. L. (2006). Mental health in adolescence: Is America's youth flourishing? American Journal of Orthopsychiatry, 76, 395-402.

Keyes, C. L. M. (2013). Promoting and protecting positive mental health: Early and often throughout lifespan. In C. L. M. Keyes (Ed.), Mental well-being: International contributions to the study of positive mental health (pp. 3-29). New York: Springer.

Keyes, C. L. M., \& Simoes, E. J. (2012). To flourish or not: Positive mental health and all-cause mortality. American Journal of Public Health, 102(11), 2164-2172.

Kim-Cohen, J., Moffitt, T. E., Caspi, A., \& Taylor, A. (2004). Genetic and environmental processes in young children's resilience and risk to socioeconomic deprivation. Child Development, 75, 651-668.

Lavy, S. (2019). A review of character strengths interventions in 21 st century schools: Their importance and how they can be fostered. Applied Research in Quality of Life. Retrieved from https://doi.org/10.1007/s11482-018-9700-6.

Levendosky, A. A., Leahy, K. L., Bogat, G. A., Davidson, W. S., \& von Eye, A. (2006). Domestic violence, maternal parenting, maternal mental health, and infant externalizing behavior. Journal of Family Psychology, 20, 544-552.

Liew, J., Chen, Q., \& Hughes, J. N. (2010). Child effortful control, teacher-student relationships, and achievement in academically at-risk children: Additive and interactive effects. Early Child Research Quarterly, 25, 51-64. https://doi.org/10. 1016/j.ecresq.2009.07.005. 
Liu, W., Tian, L., Huebner, E. S., Zheng, X., \& Li, Z. (2015). Preliminary development of the elementary school students' subjective well-being in school scale. Social Indicators Research, 120, 917-937. https://doi.org/10.1007/s11205-0140614-x.

Long, R. F., Huebner, E. S., Wedell, D. H., \& Hills, K. J. (2012). Measuring school related subjective well-being in adolescents. American Journal of Orthopsychiatry, 82, 50-60. https://doi.org/10.1111/j.1939-0025.2011.01130.x.

Luthar, S. S. (2006). Resilience in development: A synthesis of research across five decades. In D. Cicchetti, \& D. J. Cohen (Eds.), Developmental psychopathology: Vol. 3. Risk, disorder, and adaptation (2nd ed., pp. 739-795). Hoboken, NJ: Wiley. https://doi.org/10.1002/9780470939406.ch20.

Luthar, S. S., Sawyer, J. A., \& Brown, P. J. (2006). Conceptual issues in the studies of resilience: Past, present, and future research. Annals of the New York Academy of Sciences, 1095, 105-115.

Lyubomirsky, S., King, L., \& Diener, E. (2005). The benefits of frequent positive affect: Does happiness lead to success? Psychological Bulletin, 131, 803-855. https://doi.org/10.1037/0033-2909.131.6.803.

Magyar-Moe, J. L. (2009). Therapist's guide to positive psychological interventions. New York: Elsevier Academic Press.

Martinez-Torteya, C., Bogat, G. A., von Eye, A., \& Levendosky, A. A. (2009). Resilience among children exposed to domestic violence: The role of risk and protective factors. Child Development, 80, 562-577.

Masten, A. S. (2007). Resilience in developing systems: Progress and promise as the fourth wave rises. Development and Psychopathology, 19, 921-930. http://dx.doi. org/10.1017/S0954579407000442.

Masten, A. S. (2018). Resilience theory and research on children and families: Past, present, and promise. Journal of Family Theory \& Review, 10(1), 12-31.

Milyavskaya, M., \& Koestner, R. (2011). Psychological needs, motivation, and wellbeing: A test of self-determination theory across multiple domains. Personality and Individual Differences, 50, 387-391. https://doi.org/10.1016/j.paid.2010. 10.029 .

Nolan, A., Taket, A., \& Stagnitti, K. (2014). Supporting resilience in early years classrooms: The role of the teacher. Teachers and Teaching, 20(5), 595-608. https://doi.org/10.1080/13540602.2014.937955/.

Orkibi, H., Hamama, L., Gabriel-Fried, B., \& Ronen, T. (2018). Pathways to adolescents' flourishing: Linking self-control skills and positivity ratio through social support. Youth \& Society, 50, 3-25. https://doi.org/10.1177/0044118x1 5581171.

Orkibi, H., \& Ronen, T. (2015). High self-control protects the link between social support and positivity ratio for Israeli students exposed to contextual risk. Journal of School Psychology, 53(4), 283-293.

Orkibi, H., \& Ronen, T. (2017). Basic psychological needs satisfaction mediates the association between self-control skills and subjective well-being. Frontiers in Psychology, 8, 1-10. https://doi.org/10.3389/fpsyg.2017.00936. 
Pike, A., Dawley, S., \& Tomaney, J. (2010). Resilience, adaptation and adaptability. Cambridge Journal of Regions, Economy and Society, 3(1), 59-70. https://doi.org/ $10.1093 /$ cjres/rsq001.

Richardson, G. (2002). The metatheory of resilience and resiliency. Journal of Clinical Psychology, 58(3), 307-321.

Ronen, T. (1994). Imparting self-control skills in the school setting. Child \& Family Behavior Therapy, 16(1), 1-20.

Ronen, T., Abuelaish, I., Rosenbaum, M., Agbaria, Q., \& Hamama, L. (2013a). Predictors of aggression among Palestinians in Israel and Gaza: Happiness, need to belong, and self-control. Children and Youth Services Review, 35, 47-55. https://doi.org/10.1016/j.childyouth.2012.10.015.

Ronen, T., Hamama, L., \& Rosenbaum, M. (2013b). Enuresis-Children's Predictions of Their Treatment's Progress and Outcomes. Journal of Clinical Nursing, 22(1-2), 222-232.

Ronen, T., Hamama, L., Rosenbaum, M., \& Mishely-Yarlap, A. (2014). Subjective well-being in adolescence: The role of self-control, social support, age, gender, and familial crisis. Journal of Happiness Studies, 17(1), 81-104. https://doi.org/ 10.1007/s10902-014-9585-5.

Ronen, T., Rahav, G., \& Rosenbaum, M. (2003). Children's reactions to war situation as a function of age and sex. Anxiety Stress and Coping, 16, 59-69.

Ronen, T., \& Rosenbaum, M. (2010). Developing learned resourcefulness in adolescents to help them reduce their aggressive behavior: Preliminary findings. Research on Social Work Practice, 20(4), 410-426. https://doi.org/10.1177/104973150933 1875.

Ronen, T., \& Seeman, A. (2007). Subjective well-being of adolescents in boarding schools under threat of war. Journal of Traumatic Stress, 20, 1053-1062.

Rosenbaum, M. (1990). Learned resourcefulness: On coping skills, self-control, and adaptive behavior. New York, NY: Springer.

Rosenbaum, M. (2000). The self-regulation of experience: Openness and construction. In P. Dewe, T. Cox, \& M. Leiter (Eds.), Coping, health, and organizations (pp. 51-67). London: Taylor \& Francis.

Rutter, M. (2006). Implications of resilience concepts for scientific understanding. Annals of the New York Academy of Sciences, 1094, 1-12.

Ryan, R. M., \& Deci, E. L. (2000). Self-determination theory and the facilitation of intrinsic motivation, social development, and well-being. American Psychologist, 55, 68-78. https://doi.org/10.1037/0003-066x.55.1.68.

Ryff, C. D. (2014). Psychological well-being revisited: Advances in science and practice. Psychotherapy and Psychosomatics, 83(1), 10-28.

Sarason, B. R., Sarason, I. G., \& Pierce, G. R. (1990). Social support: An interactional view. New York: Wiley.

Seccombe, K. (2002). Beating the odds versus changing the odds: Poverty, resilience, and family policy. Journal of Marriage and the Family, 64, 384-394.

Seligman, M. E. (2011). Building resilience. Harvard Business Review, 89(4), 100106. 
Seligman, M. E. P., Steen, T. A., Park, N., \& Peterson, C. (2005). Positive psychology progress: Empirical validation of interventions. American Psychologist, 60, 410-421.

Shachar, K., Ronen-Rosenbaum, T., Rosenbaum, M., Orkibi, H., \& Hamama, L. (2016). Reducing child aggression through sports intervention: The role of selfcontrol skills and emotions. Children and Youth Services Review, 71, 241-249. Retrieved from http://dx.doi.org/10.1016/j.childyouth.2016.11.012.

Shannon, K. E., Beauchaine, T. P., Brenner, S. L., Neuhaus, E., \& Gatzke-Kopp, L. (2007). Familial and temperamental predictors of resilience in children at risk for conduct disorder and depression. Development and Psychopathology, 19, 701-727.

Steinberg, L. (2007). Adolescence (8th ed.). New York: McGraw-Hill.

Steinberg, L. (2013). Does recent research on adolescent brain development inform the mature minor doctrine? Journal of Medicine and Philosophy, 38, 256-267.

Suldo, S. M., Bateman, L. P., \& Gelley, C. D. (2014). Understanding and promoting school satisfaction in children and adolescents. In M. J. Furlong, R. Gilman, \& E. S. Huebner (Eds.), Handbook of positive psychology in schools (2nd ed., pp. 365-380). New York, NY: Routledge.

Tian, L., Chen, H., \& Huebner, E. S. (2014). The longitudinal relationships between basic psychological needs satisfaction at school and school-related subjective well-being in adolescents. Social Indicators Research, 119, 353-372. https:// doi.org/10.1007/s11205-013-0495-4.

Tice, D. M., Baumeister, R., Shmueli, D., \& Muraven, M. (2007). Restoring the self: Positive affect helps improve self-regulation following ego depletion. Journal of Experimental Social Psychology, 43, 379-384.

Ungar, M. (2008). Resilience across cultures. British Journal of Social Work, 38(2), 218-235. https://doi.org/10.1093/bjsw/bcl343.

Ungar, M., Ghazinour, M., \& Richter, J. (2013). What is resilience within the social ecology of human development? Journal of Child Psychology and Psychiatry, 54, 348-366. https://doi.org/10.1111/jcpp.12025.

Valiente, C., Swanson, J., Lemery-Chalfant, K., \& Berger, R. H. (2014). Children's effortful control and academic achievement: Do relational peer victimization and classroom participation operate as mediators? Journal of School Psychology, 52, 433-445. https://doi.org/10.1016/j.jsp.2014.05.005.

Van Ryzin, M. J. (2011). Protective factors at school: Reciprocal effects among adolescents' perceptions of the school environment, engagement in learning, and hope. Journal of Youth and Adolescence, 40, 1568-1580. https://doi.org/10.1007/ s10964-011-9637-7.

Waters, L. (2011). A review of school-based positive psychology interventions. Educational and Developmental Psychologist, 28(2), 75-90.

Waters, L. (2015). The relationship between strength-based parenting with children's stress levels and strength-based coping approaches. Psychology, 6 (6), 689-699.

Watson, D., Clark, L. A., \& Tellegen, A. (1988). Development and validation of brief measures of positive and negative affect: The PANAS scales. Journal 
of Personality and Social Psychology, 54(6), 1063-1070. https://doi.org/10.1037/ 0022-3514.54.6.1063.

Wehmeyer, M. L., \& Shogren, K. A. (2017). The development of self-determination during adolescence. In M. L. Wehmeyer, K. A. Shogren, T. D. Little, \& S. J. Lopez (Eds.), Development of self-determination through the life-course (pp. 8998). Dordrecht: Springer. https://doi.org/10.1007/978-94-024-1042-6.

White, M. A., \& Waters, L. E. (2015). A case study of "the good school:" Examples of the use of Peterson's strengths-based approach with students. Journal of Positive Psychology, 10(1), 69-76.

Open Access This chapter is licensed under the terms of the Creative Commons Attribution 4.0 International License (http://creativecommons.org/licenses/by/4.0/), which permits use, sharing, adaptation, distribution and reproduction in any medium or format, as long as you give appropriate credit to the original author(s) and the source, provide a link to the Creative Commons license and indicate if changes were made.

The images or other third party material in this chapter are included in the chapter's Creative Commons license, unless indicated otherwise in a credit line to the material. If material is not included in the chapter's Creative Commons license and your intended use is not permitted by statutory regulation or exceeds the permitted use, you will need to obtain permission directly from the copyright holder. 